\title{
Economías sexoafectivas: significados, prácticas y relaciones en tensión en contextos petroleros de la Patagonia argentina ${ }^{*}$
}

Sexual-affective economies:

meanings, practices, and

relationships in tension

in oil industry contexts

of Argentine Patagonia

Melisa Cabrapan Duarte*

Recibido: 18 de diciembre de 2019

Revisado: 20 de febrero de 2020

Aprobado: 15 de marzo de 2020

Cómo citar: Cabrapan Duarte, M. (2020). Economías sexoafectivas: significados, prácticas y relaciones en tensión en contextos petroleros de la Patagonia argentina. Revista CIFE: Lecturas de Economía Social, 22(37), 139-161. DOI: https://doi.org/10.15332/22484914/6044

**IIDyPCA/Conicet/unRn. Correo electrónico: mcabrapan@unrn.edu.ar. Investigación financiada por el Consejo Nacional de Investigaciones Científicas y Técnicas (Conicet), en el marco de una beca doctoral. 


\section{Resumen}

En este artículo, se analiza la configuración de las economías sexoafectivas en torno a la prostitución en contextos petroleros de la Patagonia argentina. Además, se estudian las diferentes dinámicas conyugales y familiares entre hombres y mujeres que se vincularon sexoafectivamente a través del mercado sexual o fuera de él, y que desenvuelven y sostienen económicamente sus vidas en contextos dependientes de la actividad hidrocarburífera. El objetivo es, a partir de las experiencias y discursos de diferentes actores, indagar en cómo se construye y significa la cotidianidad de esos relacionamientos, y el modo en que se expresan las tensiones entre la sexualidad, el afecto y la economía.

Palabras clave: economías sexoafectivas, conyugalidad, contextos petroleros, género, intimidad.

Códigos JEL: J01, J1, J23.

\section{Abstract}

This article analyses the conformation of the sexual-affective economies around prostitution in oil industry contexts of Argentine Patagonia. Likewise, it studies different conjugal and family dynamics, between men and women that were involved sexual-affectively through the sex-trade context or outside of it, and who developed and sustained their lives in a local economy that is dependent on the oil and gas industry. The purpose is, based on the experiences and discourses of different actors, to analyze hoy everyday life is built in those relationships, what do they mean and how the tensions between sexuality, affection, and the economy are expressed.

Keywords: sexual-affective economies; conjugality; oil industry contexts; gender; intimacy

JEL Classification: J01, J1, J23. 


\section{Puntos de partida teórico-metodológicos: entre la economía y la intimidad}

Ante la idea y sentido sociocultural predominante de que la economía y la sexualidad son o deben ser ámbitos separados, la práctica social y las relaciones entre hombres y mujeres en torno a la prostitución ${ }^{1}$ en contextos petroleros de la Patagonia argentina ${ }^{2}$ exhibe que esos aparentes "mundos hostiles", en términos de Zelizer (2009), están en constante interacción permitiendo cuestionar, incluso, que se trata de esferas distintas. A partir de esto, propongo la conceptualización de economías sexoafectivas para remitir a un universo mayor que el de la economía de mercado a la que suele quedar reducido el mercado sexual ${ }^{3}$ desde algunas interpretaciones, y referir a los marcos de significación que orientan las prácticas e intercambios económicos, sexuales y afectivos, a su vez entramados con valoraciones, obligaciones, necesidades y distintos capitales -sociales, materiales, eróticos- que se ponen en juego en la trama de relaciones entre hombres y mujeres (Bourdieu, 1997; Hakim, 2012; Piscitelli et al., 2011).

De esta manera, abordar el universo de intercambios entre mujeres de la noche $e^{4}$ y petroleros desde las economías sexoafectivas permite complejizar la discusión al enfatizar en la articulación entre las dimensiones sexuales, económicas y afectivas (Hofmann \& Moreno, 2016; Piscitelli, 2013, 2016) $)^{5}$ y ampliar el abanico de las transacciones sexo-comerciales articulándolas con otras relaciones que no necesariamente - $\mathrm{O}$ en apariencia- implican un cambio por dinero. Así, se hace referencia a un extenso universo de prácticas e intercambios sexuales, afectivos y monetarios que incluyen y al mismo tiempo superan los servicios estrictamente sexuales, incorporando las relaciones conyugales o

1 El concepto de prostitución refiere al intercambio de sexo por dinero, es decir, al sexo comercial. Sin dejar de señalar que en su etimología encubre una valoración moral negativa donde prostituir es sinónimo de 'corromper' o 'degradar', es un término genérico que retomaré en tanto proviene de otras fuentes discursivas que serán analizadas y en tanto está siendo reivindicado por colectivos de trabajadoras sexuales que abogan por el reconocimiento laboral, resignificando su carácter peyorativo original.

2 Haré referencia a distintas ciudades petroleras localizadas en la Comarca Petrolera Neuquina, que es un circuito geográfico y productivo emplazado sobre la Cuenca Petrolera Neuquina y organizado en torno a la industria hidrocarburífera, que incluye a las ciudades de Cutral-Co y Plaza Huincul, Catriel, en Río Negro, Rincón de los Sauces, en el norte neuquino, Añelo, a partir de la reciente explotación no convencional del yacimiento Vaca Muerta, y Neuquén, la capital provincial. También voy a remitirme a ciudades como Comodoro Rivadavia, donde se inició la actividad petrolera en el país, así como a Caleta Olivia, emplazadas sobre la Cuenca Petrolera del Golfo San Jorge, en tanto forman parte de los recorridos de las(os) interlocutoras(es).

3 El mercado sexual incluye una diversidad de actividades sexuales (por ejemplo: alterne, pornografía, masajes, baile erótico, sexo virtual) y supera la exclusiva referencia al sexo comercial o prostitución, en tanto contempla intercambios sexoafectivos con grados diferenciales y a veces ambiguos de transacción económica, que implican o no un contrato explícito de sexo por dinero (Piscitelli, 2005; Agustín, 2007).

4 Es un término nativo para referir a mujeres que participan en intercambios sexocomerciales en la zona petrolera.

5 Para nombrar esta articulación, Hofmann y Moreno (2016) refieren específicamente a "economías íntimas", entendiéndolas como las relaciones de proximidad (sexuales, familiares, amorosas) que interactúan con transacciones de mercado. Por su parte, Piscitelli (2016) remite a "economías sexuales", que son definidas por la autora como universos sociales más amplios donde el mercado del sexo tiene lugar y a partir de las cuales se desarrolla. 
matrimoniales, las ayudas y las diversas formas de cuidado ${ }^{6}$. A partir de lo anterior, el caso en estudio evidencia que existe un proceso de interacción entre lo percibido como íntimo y privado frente a lo monetarizado y público, y que cuya percepción y valoración es variable respecto de las subjetividades que se ponen en juego y del orden cultural y de género que opere.

Asimismo, ante esa interacción entre la intimidad y la economía, predomina el supuesto de que la mercantilización corrompe las relaciones humanas, en tanto los intercambios materiales son percibidos comúnmente como utilitarios y carentes de afecto y emociones. En este marco, la propuesta es considerar las vidas conectadas (Zelizer, 2009) y, a través del método etnográfico, observar cómo las esferas de lo público y lo privado están vinculadas y, al mismo tiempo, conflictuadas por la dimensión económica, e indagar en el contínuum íntimo-impersonal.

En el libro La negociación de la intimidad, Zelizer (2009) sostiene que en ese contínuum las personas mezclan las actividades económicas con dimensiones de la intimidad y crean, imponen y renegocian diferenciaciones entre lazos sociales, sus límites y su adecuada combinación con los medios económicos y las transacciones de producción, consumo y distribución. Es así como estudiar la prostitución desde el enfoque de las economías sexoafectivas posibilita indagar en el modo en que las prácticas consideradas privadas están atravesadas por el dinero y, en consecuencia, asumen una condición mercantilizada, a su vez supeditada a valoraciones morales. No obstante, es fundamental recordar el señalamiento teórico de que la mercantilización de la intimidad no debe ser un fin analítico en sí mismo sino un punto de partida para estudiar relaciones sociales marcadas por el género y por el poder, y configuradas socioculturalmente de maneras específicas. Es decir, si bien la dimensión económica de la intimidad es determinante en ese proceso de volverse mercancía, resulta más alentador indagar cómo la mercantilización de las relaciones es comprendida y experimentada por quienes participan en tales relaciones y procesos.

Por su parte, la tendencia a disociar la intimidad (privada) del mercado (público), y de percibir negativamente su relación a partir de una valoración moral de las buenas o malas y verdaderas o falsas intimidades, también responde a un orden de género ${ }^{7}$ que construye la división entre lo privado y lo público. Esa separación es la expresión de la construcción cultural de la diferencia sexual (Strathern, 2006) y de la división sexual

6 Desde la economía y teoría feminista, el care ('cuidado') comenzó a ser leído como central en y para el trabajo reproductivo - y no remunerado- que implica tareas de cuidado realizadas habitualmente por las mujeres y que pueden, en muchas ocasiones, estar superpuestos con interdependencias afectivas guiadas, a su vez, por marcos morales y "reglas del sentir" (Abramowski \& Canevaro 2017; Hochschild, 1979; Rodríguez, 2012; Vega \& Gutiérrez Rodríguez, 2014; Zelizer, 2008).

7 Retomo la conceptualización de Serret (2006) donde el género es un ordenador simbólico e imaginario de lo social y de las identidades, basado en la oposición femenino-masculino, que crea categorías de distinción y, al mismo tiempo, las jerarquiza a partir de las valoraciones que produce respecto de los significados. 
del trabajo que, a su vez, les asigna a las mujeres como "natural" el espacio doméstico y a los hombres el ámbito externo al hogar, de lo productivo y del poder (Mead, 2006; Ortner, 1972; Rosaldo, 1979). Al respecto y tal y como señala la geografía feminista, son las relaciones de género, poder y exclusión las que establecen normas, definen los límites y configuran espacialmente la vida social (Massey, 1994; McDowell, 2000).

De este modo, más allá de la efectiva escisión de los espacios por las correspondencias cuasi biológicas con los sexos, la antropología feminista, así como otros abordajes del tema desde las ciencias sociales, han analizado la esquematización de la vida doméstica (femenina/feminizada) y la vida pública (masculina/masculinizada) como dominios diferentes. Durante los años sesenta y setenta, estos abordajes contribuyeron a observar y señalar las complejidades y problemáticas en los ámbitos de las mujeres, restituyéndoles politicidad y cuestionando la subordinación, los argumentos biologicistas, y los dualismos entre lo privado y lo público, lo reproductivo y lo productivo, lo gratuito y lo remunerado, lo emocional y lo racional. En efecto, Jelin (1984) señaló que "la familia y las relaciones domésticas cotidianas no constituyen un mundo privado. Más bien, el mundo privado de cada sujeto social se construye a partir de las relaciones y controles sociales dentro de los cuales desarrolla la cotidianeidad" (p. 40).

Así, considero la intimidad como un conjunto de "relaciones sociales que son -o dan la impresión de ser- físicamente y/o emocionalmente cercanas, personales, sexualmente íntimas, privadas, cariñosas o amorosas" (Constable, 2009, p. 50) y donde, si bien la intimidad no está necesariamente asociada o limitada a lo doméstico, se la percibe socialmente como dentro del ámbito de lo privado. Asimismo, en tanto la definición social de lo íntimo, lo privado, lo familiar y lo económico está supeditada a los marcos morales que orienten la producción de significado, se vuelve inevitable recurrir a un análisis sobre la dimensión moral.

Esto permitirá abordar esos tránsitos y mundos entremezclados entre economía e intimidad y dinero y sexo-afecto, como regulados por moralidades descriptivas y performativas, que producen vocabularios, valores, subjetividades y mundos morales (Balbi, 2007; Fassin, 2012), a su vez intrincados con procesos históricos, económicos, políticos, y de género.

Por otro lado, a lo largo del trabajo de campo desarrollado durante mi investigación doctoral fui conociendo a distintas mujeres, tanto mujeres de la noche, como exmujeres de la noche, e involucrándome y generando lazos de amistad y confianza con ellas ${ }^{8}$. Esos vínculos y la constante interacción durante mi permanencia en la comarca y, en particular, en Rincón de los Sauces, me permitió conocer sus experiencias personales y

8 Forma parte de la reflexión metodológica etnográfica, así como también epistemológica, el involucramiento afectivo con los(as) sujetos(as) con los que estudiamos determinadas problemáticas sociales y las implicancias que esto tiene en la producción de conocimiento (Callaway, 1992; Irwin, 2007). 
percepciones respecto de sus relaciones sexoafectivas y del lugar que estas ocupan en sus vidas cotidianas. Así, muchas de nuestras conversaciones giraron en torno a las parejas, las búsquedas, los intereses y las implicancias de la conyugalidad.

Parto de considerar el matrimonio o las diversas formas de relación en torno a este o para llegar a este, como situaciones emblemáticas de las relaciones entre hombres y mujeres, que desde su configuración en lo privado expresan dimensiones organizativas, estructurales y simbólicas de la vida social, reafirmando el lema feminista heredado de que lo "personal es político". En este sentido, como señala Brook (2015), "la historia del compromiso feminista con el matrimonio casi equivale a una historia del pensamiento feminista en general" (p. 12) en tanto la conyugalidad "puede entenderse ciertamente como, en algunos aspectos, emblemática de las relaciones más amplias que se mantienen y construyen en las relaciones de sexo, sexualidad, identidad y política” (p. 28).

La autora sostiene que si bien ha predominado desde el feminismo la concepción de que el matrimonio es una institución patriarcal, opresiva y de explotación para las mujeres (Delphy \& Leonard,1992), así como violenta -e incluso una violación- (Dworkin, 1989), y que representa el "contrato sexual" (Pateman, 1995)9 , también han surgido lecturas críticas de la mano de los cambios sociopolíticos y por los derechos conquistados. Estas cuestionan, por ejemplo, el rechazo generalizado al matrimonio, indagando en las posibilidades de agenciamiento de las mujeres - así como de identidades gay, lesbiana y trans con el matrimonio igualitario- ${ }^{-}$, con base en ello, Brook propone analizar el matrimonio a través de un abordaje que lo interrelacione con la gubernamentalidad, la corporalidad y la performatividad. Sin embargo, si bien la autora se refiere a algunos aspectos que involucran la dimensión económica, no le presta atención exclusiva como estructurante de la conyugalidad, al contrario de lo que permite la perspectiva desde las economías sexoafectivas, para reflexionar acerca de los mercados matrimoniales, por ejemplo. Desde este enfoque analítico, cualquier forma de relacionamiento sexoafectivo, cuyo grado de formalidad y características vinculares son diferentes, está en interacción con la dimensión económica de esas interacciones, aunque de modo variable según el contexto y los actores que participen en esas relaciones.

Por ejemplo, la investigación de Constable (2003) sobre los matrimonios "por pedido y correspondencia" entre mujeres filipinas y chinas y hombres norteamericanos en el contexto contemporáneo señala que esas uniones están vinculadas a patrones más amplios de economía política, además de ideas de amor y deseo. De este modo:

$9 \quad$ Para Carole Pateman la institución del matrimonio implica un contrato, que "es el medio específicamente moderno de crear relaciones de subordinación" (Pateman, 1995, p. 165). Para la autora, la esfera privada se constituye en el matrimonio a través del "contrato sexual", en contraposición -y también complemento- con el espacio público, donde el "contrato social" regula y organiza el trabajo y donde son los varones los que tienen el poder a través del derecho patriarcal, soporte estructural que une esas esferas. 
El desafío etnográfico es cómo tener en cuenta las desigualdades estructurales y los factores socioculturales que circunscriben las opciones de mujeres y hombres, e inspiran nuevas oportunidades e imaginaciones, al tiempo que transmiten la riqueza y la dignidad de sus opciones, sin reducirlas al cálculo instrumentalista o romántico ingenuo. (Constable, 2003, p. 217)

De esta manera, compartir con las mujeres diversos momentos e intensas charlas posibilitó conocer una multiplicidad de sentidos sobre sus relaciones conyugales, que no se limitan ni al interés material ni al romántico; por el contrario, entremezclan las obligaciones como esposas y madres, los diversos arreglos con los maridos, y también la importancia de lo sexual, lo afectivo y lo económico para la búsqueda de una pareja o en el comienzo o desenvolvimiento de una relación formal. Me centraré en la expresión económica, aunque la distinguiré con una finalidad analítica, reconociendo su inevitable interacción discursiva y práctica con otros aspectos. Por ejemplo, para Laura y Gimena, migrantes paraguaya y peruana respectivamente, y ambas exmujeres de la noche, el interés y amor de los hombres se demuestra con "lo que te dan". Así como expresa Martino, un expetrolero chileno, actual comerciante y transportista que le alquilaba cuartos a las mujeres de la noche, cuando dice que:

Tanto amor no hay, que todo el amor es por la plata, y esa es la realidad. [...] Es un negocio. Este pueblo tiene de todos los negocios que puede haber, y todo da vuelta alrededor del sexo y la plata. La plata manda acá. Acá, si no hay plata, no manda. (Martino, comunicación personal, 2018)

No obstante, no es suficiente con indagar la calidad material de los intercambios, sino que la dimensión simbólica, tal y como la etnografía clásica de Mauss (1979) lo demuestra, expresa que las transacciones están regidas tanto por la economía como por la moral, y también se relacionan con variaciones socioculturales e históricas. Así, analizar el carácter económico de los intercambios íntimos implica tomar distancia de la concepción de economía de mercado y su lógica racional, calculada e individualista, para priorizar la economía moral que "asigna papeles económicos y que aprueba prácticas consuetudinarias (una economía alternativa) en un equilibrio determinado de fuerzas de clase o sociales" (Thompson, 1995, p. 382). En este marco, observar cómo se producen y operan las economías sexuales y morales, e indagar el modo en que actúan y significan sus acciones quienes participan en ellas, permite dar cuenta de las movilidades espaciales y sociales de los sujetos a partir de esas interacciones socioeconómicas. Narotzky \& Besnier (2014) redefinen la economía como "un conjunto de procesos que, de una manera u otra, están involucrados en 'ganarse la vida' tomados en un sentido muy amplio y enfatizando tanto el 'esfuerzo' involucrado como el objetivo de 'sostener vida" (p. 5). Para los autores, esta comprensión ampliada de la economía atiende a las actividades humanas más allá de lo estrictamente material incluyendo en el análisis otros regímenes de valor que coexisten con el del cálculo y la ganancia. 
A continuación, abordaré distintos discursos de mujeres y hombres que se vincularon sexoafectivamente a través del mercado sexual -como mujeres de la noche y clienteso fuera de él, y que desenvuelven y sostienen económicamente sus vidas en contextos dependientes de la actividad hidrocarburífera. A partir de recuperar y poner en diálogo sus experiencias, el objetivo es indagar en cómo significan los involucramientos sexoafectivos y las dinámicas conyugales, más o menos formales, pensándolos como modos de "sostener la vida" que tienen múltiples implicancias y expresiones de género.

\section{Vidas entremezcladas para "sostener la vida": ¿una cuestión de suerte?}

Cuando conocí a Reina, una noche de pleno invierno y en uno de los últimos cabarets que se mantuvo abierto durante un tiempo pese a la prohibición ${ }^{10}$, no le faltaban los clientes. Este local era prácticamente de dominicanas, como lo es Reina, es decir, tanto las mujeres de la noche como la que atendía la barra tenían este origen nacional. Después, cuando los bares fueron clausurados por la rigurosidad que tomó la normativa antitrata, y como efecto de la re-espacialización del deseo (Cabrapan \& Jiménez, 2020), Reina comenzó a salir a los lugares sin explícita oferta sexual, como el casino y las bailantas, donde tenía posibilidades de trabajar, así como de conocer a alguien para una relación formal. Además, tenía sus amigos y pretendientes que la buscaban y le daban ayudas, pero ninguno satisfacía sus expectativas o la cuidaba como ella quería. Actualmente sale con uno de esos amigos que, después de estar desempleado por meses y de mucha insistencia, pudo ingresar a una empresa petrolera.

Reina está trabajando en un puesto de comidas camino a Añelo, a 100 kilómetros de Rincón de los Sauces, con una señora con la que se queda durante los días hábiles, y también cuida temporalmente a niños(as) y adultos(as) mayores. Me cuenta que con estos trabajos no gana mucho, pero que le sirve para cubrir sus gastos y los de sus hijos. El mayor de ellos vive en República Dominicana, estudia en la universidad y el menor, de 19 años, llegó hace un año a vivir con ella, después de crecer en Bahía Blanca, primer destino en Argentina al que Reina arribó hace 20 años, desde Santo Domingo. Reina es una mujer muy simpática y cariñosa, le gusta compartir historias y comidas típicas de su país, que tuve la suerte de degustar durante nuestros amigables encuentros. Así, estos se convirtieron en algo más que interacciones con fines de investigación, generaron entre nosotras cercanía y confianza mutua, y me permitieron conocer un poco más la intimidad de Reina, sus experiencias amorosas y también sus búsquedas al respecto. Las mismas se entremezclan con sus formas de participación en la noche de Rincón, ya sea 
a través de un intercambio sexoeconómico explícito o por las relaciones que superan esa transacción pero que, a la vez, son habilitadas, en buena parte, por los espacios con oferta sexual.

Forma parte de nuestras charlas de amigas sobre deseos del futuro y anécdotas del pasado, cargadas muchas veces de sufrimiento por las múltiples condiciones de desigualdad - económicas, raciales, de género-', pero también con aciertos y posibilidades de mejorar la vida, la búsqueda de una pareja estable y de encontrar un "buen hombre". Reina dice que no quiere a alguien con dinero o por el dinero, pero sí a alguien que tenga trabajo, un ingreso propio y que, sobre todo, la quiera, trate bien, y puedan disfrutar. De esta manera, la expresión de este deseo, más o menos vinculado con el interés económico, varía según la persona. Es decir, mientras Reina expresa no darle prioridad al dinero en una relación, para Laura y Gimena este ocupa un lugar fundamental.

No obstante, como ellas dicen, un "buen hombre" o una "buena pareja" es alguien que les garantiza seguridad económica y bienestar, pero además es un marido y padre cariñoso; es decir, atento afectivamente y presente en la medida que pueda, dadas las exigencias de la labor petrolera, en caso de tratarse de un trabajador de la industria de hidrocarburos, como sucede habitualmente en la comarca. Respecto de esto, Gimena siente que tuvo suerte por haber tenido y construido una buena relación, y por haber desarrollado un proyecto de vida personal y familiar, porque, por ejemplo, si bien inicialmente vivió con Jorge en el lugar que ella alquilaba, después compraron un terreno -en buena parte debido a su insistencia, como dice--, donde construyeron su casa.

De esta manera, encontrar una "buena pareja" o "casarse bien" supone no solo el mandato de género (donde el valor está puesto en el rol de esposa y madre de familia o se trata de una búsqueda orientada por la idea del amor romántico), sino también el objetivo de hallar un buen proveedor, que pueda cubrir o satisfacer las necesidades materiales y legales cuando ellas están en posiciones desiguales: de clase, de raza - en tanto son migrantes latinoamericanas y caribeñas- y por la exclusión o segmentación laboral que genera el estigma de "puta", en el caso de las mujeres de la noche.

A su vez, como sostiene Hiller (2016), la conyugalidad genera efectos diferenciales en la ciudadanía y en el ejercicio de derechos, y más en contextos petroleros como Comodoro Rivadavia, que es su caso de estudio, atravesados por fuertes asimetrías entre varones y mujeres. Esto implica que las relaciones matrimoniales validadas por el Estado adquieran un estatus y reconocimiento social y moral y sean reguladas a través de leyes, burocracias y políticas públicas, lo que hace de la conyugalidad un dispositivo de control. Pero, al mismo tiempo, existen otras regulaciones no estatales, como las del mercado o economía predominante (hidrocarburífera), que operan en conjunto con la reproducción y redefinición del orden de género. En este sentido, podemos entender las relaciones conyugales -formales o informales- y su búsqueda como formas de "sostener 
la vida" (Narotzky \& Besnier, 2014), así como modos de agenciamiento por la movilidad económica y reconocimiento social que provocan (Piscitelli, 2013).

Cabe decir que, en primer lugar, este panorama no solo aplica para mujeres de la noche y petroleros, sino que la conyugalidad, tanto su pretensión como sostenimiento, organiza las relaciones sociales en general en contextos con actividad hidrocarburífera; en segundo lugar, a pesar de que la institucionalización del vínculo a través del casamiento o concubinato no sea la tendencia en la comarca, esto no excluye los beneficios o privilegios de un matrimonio, y estos varían según la situación y los arreglos de la pareja. Bajo esta óptica, veo el caso de Katy, cuyas experiencias ponen en diálogo su trayectoria migratoria, las posibilidades laborales, las permanencias en distintas ciudades petroleras de la Patagonia, y sus vínculos sexoafectivos y conyugales cambiantes. Ella es peruana, y llegó a la Argentina en el año 1996 junto al que, en ese entonces, era su marido desde los 17 años, y padre de tres de sus hijos, uno nacido en Perú y los otros dos en Mendoza (Argentina). Migraron a esta ciudad porque buena parte de la familia ya lo había hecho, principalmente las mujeres, tanto su madre como sus tías, y ella se preguntaba “¿qué había acá que todo el mundo venía?".

Trabajó en el servicio doméstico en cuanto arribó al país, "porque es lo primero que encontrás" y "lo que hicieron todas las compatriotas", y vivió en una casita que les prestaron en una villa. Recuerda esas épocas como tiempos muy difíciles, por la necesidad económica y también por la violencia que vivió en su relación con un "machista jodido", del cual su madre le ayudó a separarse "sacando la garra", aunque él ejerció mucha resistencia. Sumado a esto, experimentó constantes situaciones de acoso laboral y sexual por parte de los patrones, profesionales todos (abogados, médicos), y tanto extranjeros como argentinos. Dijo que no hizo nada ante esto porque era muy inocente y porque tenía vergüenza; ni siquiera pudo compartirlo con su mamá cuando uno de ellos la fue a buscar hasta su casa porque había dejado de ir a trabajar. No obstante, después de que pasó el tiempo y tuvo más edad, pensó: “¡Cómo no me avivé! Si imaginate, era un italiano, era divino el hombre. Me ofreció el oro y el moro, y yo ¡no!”. Esto tiene relación con lo que vendría después, cuando conoció una manera distinta de relacionarse con los hombres.

Katy cuenta que se fue a trabajar a Buenos Aires, a través del mismo contacto que le conseguía los trabajos en el servicio doméstico y, aprovechando la oportunidad para alejarse de su exmarido, dejó a sus hijos al cuidado de su madre y de algún modo recuperó su libertad e independencia. A partir de esta experiencia, cuando una amiga la invitó a ir al sur con otras mujeres, específicamente a Comodoro Rivadavia, ella aceptó, y aunque no sabía a dónde estaba yendo la sedujo la idea de que allá se ganaba mejor y que tenían a dónde llegar y vivir. Cuenta que les consiguieron trabajo como empleadas y que empezaron a salir, a "hacer la suya" y a ver otras cosas: 
¡Había plata, joda, de todo, hombres! ¡Era la princesa! Pero en serio te digo. Siempre me quedé con eso [...] Y en ese tiempo, nosotras éramos jovencitas, todas jóvenes y lindas. ¡Qué se yo! Teníamos un montón de pretendientes. Y entonces, económicamente, me daban lo que yo quería, viste. Y entonces me empezó a gustar esa vida. "Te doy acá, te doy todo, ¿qué querés? ¿pasaje? ¿querés esto? Que no sé cuánto, que no trabajes, que nos vamos de joda”. Porque había dinero, ¿entendés? (Katy, comunicación personal, 2018)

En esas interacciones de las que habla Katy, se ponían en juego distintos capitales, entre ellos, el económico y erótico. Mientras eran habitualmente los hombres - con altos sueldos provenientes de la industria petrolera- los que detentaban el primero, las mujeres tenían el segundo. Hakim (2012) señala que el capital erótico "combina belleza, sex appeal [atracción sexual], dinamismo, talento para vestirse bien, encanto, habilidades sociales y competencia sexual. Es una mezcla de atractivo físico y social. La sexualidad es parte de él" (p. 16). Como señala la autora, el capital erótico no lo tienen solo las mujeres, sino también los hombres, y varía socioculturalmente, así como con relación a diferencias espacio-temporales. Además, a pesar de no ser propio del mercado sexual, esta 'industria occidental del entretenimiento', como la autora lo llama, se ofrece y se vende junto a "excitación, emociones extremas, intriga, chismes, conocimiento, enigmas, fantasía, imágenes y música, alegría y felicidad” (Hakim, 2012, p. 168). En este marco de intercambios, el objetivo es que el hombre gaste su dinero a cambio del capital erótico ofrecido en ese espacio.

Asimismo, en las relaciones sexoeconómicas y afectivas que se salen de ese contexto explícito de oferta sexual, también se contempla que los hombres continúen proveyendo el dinero, a pesar de que los intereses estén más claramente entramados con la búsqueda de atención, seguridad, sexo, amor o afecto que esas interacciones puedan provocar. A partir de ello, las economías sexoafectivas nos permiten pensar los marcos de relacionamiento de los contextos petroleros, donde parecería no existir especificidad que distinga las relaciones del mercado sexual de otras, si todas ellas - o buena parte- entremezclan los mismos componentes.

Por ejemplo, Katy cuenta que, a los 23 años, en Comodoro Rivadavia, no le faltaban las opciones, y de hecho tenía para elegir. A pesar de que nunca se fijó en "un seco", es decir en uno que no tuviera dinero, cuenta, entre risas, que le gustaba el "más seco" entre todas las opciones que tenía: "era bastante pícara yo, ya no era más una tonta. Y [había] otro chico que estaba enamorado de mí y bueno, y había otro que era un señor". Todos ellos le daban lo que ella quería: maquillaje, viajes, comida, buenas salidas, e incluso lo que necesitara enviarles a sus hijos que estaban en Mendoza. Tanto ella como sus amigas disfrutaban los beneficios de tener amigos o pretendientes que trabajaban en distintas empresas y cenaban en los mejores restaurantes de los hoteles: "vivíamos comiendo con sus vales de Shell", dice Katy. 
Esta etapa de su vida es recordada por ella con mucha alegría por la diversión que vivió y por la sensación de libertad que tuvo, sin haberlo experimentado antes por haber sido madre tan joven, y por la situación económica y familiar en la que se encontraba. En el sur conoció personas que la trataron muy bien, y de ahí expresa haber tenido mucha suerte porque, en contraste, cuando era "más inocente y buena" la "trataron para el traste". Así, Katy tuvo opciones para elegir con quién quedarse, aunque a la vez, aprovechó lo que cada uno le dio, y en simultáneo. Pero su época de "mantenida" por más de uno se terminaría cuando su madre ya no se pudo ocupar más del cuidado de sus hijos, de 6, 7 y 9 años, por problemas de depresión. Fue ahí donde se preguntó cómo iba a hacer y tuvo que elegir entre los que la rodeaban. Al que más "la movía" no le gustaban los chicos; otro, estaba casado y tenía su familia y aunque le ofreció ponerle una casa, ella no quiso ser solo la amante; sus compadres le dijeron que llevara a sus hijos a Comodoro y que vivieran con ellos, pero incluso así, ella necesitaría salir a trabajar. La mejor opción fue Alan:

"Vamos a mi casa en Caleta" [una ciudad a 80 kilómetros]. ¡Ay!, la pensaba, y la pensaba, porque era la única opción. Y él era soltero, tenía un buen trabajo, era joven, ya tenía todo [...] Entonces, dije: "no, acá, este que está muerto conmigo, listo". Y, así que agarré, fui a buscar los chicos [...] Y bueno, me instalé con él. Porque no me quedó otra. Y entonces, me fui a un barrio muy lindo, a un barrio muy bonito. Y me llevó. Fue lo peor que hice. Fue una experiencia mala, porque sin amor, eh, no, no funciona la vida. Una jaula de oro, ponele. Porque no es que era millonario, sino que me dio todo. Me dijo: "mirá, estas son las tarjetas, este es el crédito, este es el débito, vos manejate, vos manejate [...] Mi plata es tu plata y vos manejate como quieras, a mí no me saques cuentas, manejate". En la semana vino con las tarjetas, y eso. Pero extrañaba mucho yo, mi libertad. (Katy, comunicación personal, 2018)

A partir de este cambio, Katy no solo tuvo que volver a ocuparse directamente de sus hijos después de haberse acostumbrado a la soltería y a las posibilidades que esta dispuso para ella en términos sexoafectivos, económicos y de ocio y distracción, también debió amoldarse a una vida cómoda pero carente de esos elementos que tanto disfrutaba. Como expresa, esta pareja, con la que luego se casó, aunque era joven llevaba tiempo en el trabajo petrolero y ya ocupaba el puesto de encargado de turno en el equipo de perforación con operaciones en Comodoro Rivadavia, por lo que trabajaba por diagrama. Los pocos días que regresaba a la casa no eran suficientes para que Katy no se sintiera sola y más en una ciudad y barrio donde vivían las familias de los jefes, y donde no tenía nada para hacer. Dice que la gente era muy "nariz parada" y no tenía amigas, solo una vecina a la que nadie quería porque era "la chismosa del barrio", pero que era la única que no la miraba con desprecio. Katy sostiene que esos prejuicios hacia ella eran porque salía con un hombre más joven, que la gente sabía que los hijos eran solo de ella y que quizás también porque era extranjera, peruana, con el estigma que esto conlleva en el país y en el sur en particular. 
Este tipo de estigmatizaciones han sido analizadas por Barrionuevo (2016) que indaga en cómo se construye la identidad femenina en una región petrolera donde predomina el trabajo masculino, y donde la presencia empresarial estatal, desde 1910, ha configurado relaciones de poder patriarcales asignando roles específicos para los hombres y para las mujeres a través de sus políticas de intervención. En este marco, la autora atiende a las representaciones actuales sobre las esposas de los petroleros -en particular, de los de menor jerarquía, como los 'boca de pozo’- en Comodoro Rivadavia, y sus prácticas. El discurso social las ubica como malas esposas, malas amas de casa o malas madres con base en la desatención hacia los maridos o descuido estético de sí mismas, por no ocuparse de las obligaciones domésticas y de la maternidad (por ejemplo, prepararle la vianda al esposo para el campo o cocinarles a los hijos), mientras el hombre se ocupa de las productivas. De esta manera, la estigmatización hacia ellas se produce, en primer lugar, porque no cumplen con la aptitud cuasi natural femenina, y con el mandato moral y de género de ocuparse del hogar satisfactoriamente.

Por otro lado, como señala Barrionuevo, las representaciones negativas sobre las esposas de los petroleros de bajo rango se producen como efecto del:

[...] desacople entre capital económico y capital cultural, en el contexto específico de una ciudad petrolera y patagónica, [que] reorganiza las relaciones de género y de clase; generando desigualdades sociales que son legitimadas en distintos grados según grupos y situaciones de interacción. (Barrionuevo, 2016, p. 92).

Barrionuevo habla del desprecio de la clase media comodorense dedicada a otro sector económico - comerciante, estatal- que recae sobre el trabajador petrolero del área de perforación que protagoniza una movilidad social a partir de sus ingresos económicos, más no de sus estudios o capital cultural. Pero este desprecio no está explícitamente dirigido a los trabajadores, en tanto son ellos los que sostienen la economía de la ciudad y de la región, sino que se manifiesta hacia sus esposas a partir de sus comportamientos. Esto sucede, por ejemplo, cuando ellas participan en espacios de consumo de la élite, donde son catalogadas como "derrochadoras", "sucias", "teñidas", y en los relacionamientos sexoafectivos, como "caza-petroleros", "gordas" e "interesadas"; de ahí que Katy haya percibido ese desprecio en un barrio acomodado socioeconómicamente, en Caleta Olivia.

Sin embargo, también cabe señalar que ese desacople, socialmente percibido y castigado, entre capital económico y capital cultural de los petroleros y de sus familias también aplica en lo que refiere al capital económico de los hombres y a la ausencia de capital económico -aunque sí erótico- de las mujeres. Veamos específicamente cómo se expresan estos sentidos desde los mismos trabajadores de la industria de hidrocarburos que, a su vez, resuenan también en la comarca neuquina, sobre el interés femenino generalizado de involucrarse formalmente con un hombre proveedor. Cabe decir que esto se 
expresa en prejuicios y en representaciones negativas de las mujeres que entremezclan aspectos económicos, por ser interesadas; de género, por sus comportamientos inapropiados como mujeres; y morales, por cómo se valoran las prácticas, específicamente las que hacen en torno a los relacionamientos sexoafectivos. Gerardo, que trabaja en el área de Seguridad e Higiene de la empresa Yacimientos Petrolíferos Fiscales (YPF), dice desde su subjetividad masculina:

Yo tengo muchos amigos. Hay uno, un compañero, que te dice: "yo no me caso nunca más, yo, si quiero ponerla, pago. Me sale más barato". Hasta [está] enamorado de la pendeja allá, de Neuquén, como cliente, enamorado el X [refiere a un sobre nombre], X le decimos. "No, no me junto más, gorda hija de puta me sacó hasta el auto", decía. Después, otra del rubro del petrolero: las particulares y las profesionales. Hay minas que tienen 3, 4 pibes con diferentes [hombres] y andan con carterita Prune. Esas son las particulares. Me decía: “¡Cuidado con las particulares, cuidado! No te enganches”. Porque yo llegué a Rincón, y salís, todo y querés engancharte algo. Y ¡claro, bota petrolera, camioneta! Te ven y dicen: "Este la junta [...]". Quizás sos un gordo, feo, viste. ¡Pero! Entonces decían: “¡Guarda con las particulares, no te enganches con ellas!” (Gerardo, comunicación personal, 2016)

Así, Gerardo y sus compañeros distinguen entre las "profesionales" y las "particulares", como ellos las llaman. Las primeras son las que tienen una participación clara en el mercado sexual y donde el sexo-afecto que ofrecen está mediado explícitamente por el dinero o por una retribución económica para ellas, previamente pautada. Mientras que las "particulares", a pesar de también tener intercambios sexoafectivos con hombres de altos ingresos por su labor y recibir beneficios económicos por esas relaciones, no se adscriben ni son representadas por otros desde la prostitución. No obstante, ambas son percibidas como oportunistas e interesadas, y sus prácticas sexuales son juzgadas negativamente (se las considera "putas"), mientras que su cálculo racional y material se califica como "evidente" cuando, teniendo capital erótico y todo lo que este implica (belleza, atracción sexual, simpatía, sociabilidad), se vinculan con hombres que no lo tienen o tienen poco, como lo ejemplifica Gerardo, pero que sí detentan el capital económico que ellas no poseen.

Ante estos imaginarios, más o menos cercanos a la realidad, sobre las esposas de petroleros o en contextos petroleros, Hugo, otro trabajador de la industria petrolera, camionero, cuenta que a la hora de formar una pareja prefiere involucrarse con una mujer que tenga un capital económico propio, porque si tiene "40, 50 años, y no tiene donde caerse muerta, esa mujer no sirve, porque ¿qué hace en su vida? Nada, entonces anda por ahí, no estudió, ni siquiera se casó, ni se separó, ni ligó una casa, entonces anduvo perdiendo el tiempo". De este modo, el petrolero, a partir de las interacciones que ha tenido con mujeres, señala la importancia del dinero en una relación: "el dinero tiene que estar presente, siempre, porque es parte de todo un equilibrio", y de sus preferencias 
de encontrar a alguien que haya adquirido un capital, sin importar el modo en que lo hizo: si a través del estudio, del trabajo, o de otro hombre. Y, por otra parte, le resulta fundamental tener una compañera "con una vida propia" y que trabaje, para tener de qué conversar y porque "tener una mujer para mantenerla es muy pesado". Hugo pasó esta situación cuando se juntó con una mujer de la noche pero, como cuenta, el problema no fue que él la mantuviera a ella, a su hija y que colaborara con el envío de remesas a su familia en Paraguay, sino que:

Estaba todo el día mirando televisión, acostada. Llegaba yo y estaba todo [...] ¡No, había de todo! Cartera, paquetes de cosas, un montón, un quilombo, la cama sin hacer, acostada. Y no me gusta, no me gusta ese panorama. Y después, los domingos, que estás de franco, a las 8, las 9 me levantaba, viste, y ya me ponía a cocinar. Y llamar para comer. Una [la hija de ella] había tomado la leche como a las 11, la otra: "no, yo voy a comer más tarde” y yo solo sentado acá. Y viste, no es así ¿Pasaba eso en tu casa, comer al mediodía juntos, un domingo, tallarines? [le preguntaba él] "Sí, pero no le doy importancia. ¿Cuál es la diferencia de comer ahora, de comer más tarde, a las 3 de la tarde?" [le contestaba ella] Pero sí, para mí la diferencia es que acá estamos para no perder la tradición, la familia. Los domingos para mí hay que estar todos juntos. Y empezaban las diferencias, la tirantez. Y cuando empieza la tirantez, las cosas cotidianas, que no te podés poner de acuerdo, y eso, se discute. Que te vas, yo me voy a dar una vuelta. Y luego ya se empieza a ir el deseo de tener sexo a raíz de eso, y de a poco se va perdiendo lo que, en principio, la atracción. Y ahí me di cuenta que uno no debe juntarse solamente para tener sexo, o para que no la tenga otro, o para, ahí aprendí. O sea, sí me puedo enamorar de una mujer de la noche [porque comenzó la entrevista diciendo que no], pero me meto con una del $80 \%$ que no les gusta hacer nada, que son vagas. (Hugo, comunicación personal, 2018)

De este modo, Hugo esperaba que su expareja tuviera otro comportamiento, uno "propio de una mujer": de mayor cuidado y atención hacia él y con la casa, y un rol femenino acorde para la convivencia familiar. A partir de su propia experiencia, remite a una serie de cuestiones que también forman parte de las representaciones sobre las mujeres de la noche en particular, pero que se extienden a todas las mujeres. Es decir, si bien él se está refiriendo a las características que tiene un supuesto 80 por ciento de las mujeres de la noche - estadística que elaboró con compañeros y amigas que conocen el entorno- es posible encontrar estas percepciones aplicadas a todas o a ciertas mujeres que viven en estas localidades. Las mismas se expresan en discursos de hombres, pero también femeninos, a partir de otras interacciones y perspectivas sobre el tema. Por ejemplo, Sara es abogada y llegó a Rincón de los Sauces desde La Plata hace 5 años para vivir con su marido, que trabaja en la comarca hace alrededor de 20 años. Ella me habló sobre los casos que atiende, la mayoría de derecho de familia, y me contó lo que observó desde que llegó: 
Te voy a plantear lo que vi acá. Este es un pueblo muy machista, muy machista [...] Entonces, acá tenés mucha violencia y que, además de la física y psicológica, mucha violencia económica. Porque el que labura es el hombre, es el tipo, ¿entendés? Porque, aparte, la mayor parte del trabajo es masculino [...] Entonces, el tipo gana 40, 60, 30, según la empresa y la mujer no labura. O sea, o sea muy poquitas las mujeres que trabajan ¿Por qué? Y, porque el sueldo de él alcanza. Entonces la mina se queda en la casa, cuidando a los pibes. Entonces, después el tipo jode con la plata. Entonces, después viene la violencia psicológica, y el tipo jode con el dinero "iQue vos no hiciste nada, mirá como están los chicos, que están sucios!” ¡Los chicos se ensucian! Mirá la calle de tierra. Entonces, viste: "No haces nada, la casa está sucia, llegué cansado de trabajar y no cocinaste" ¿Me entendés? Y cosas así. Y empieza primero a tratarte de inútil, que no haces una mierda, que la, la, la, la, tenés $2,3,4,5$ pibes, sin lugar a dónde me voy. También hay violencia física, pero yo creo que lo que más predomina es la violencia económica y la psicológica. Ahí tenés todo. Entonces por ahí el tipo se va, no le pasa alimento, o por ahí le da 2 o 3 mangos que no te alcanza. Y vienen acá porque no te alcanza. (Sara, comunicación personal, 2016)

Aquí, Sara hace referencia a cómo las tareas reproductivas y productivas están estrictamente feminizadas y masculinizadas como también sucede en otros contextos, pero con mayor recurrencia y distinción en la comarca petrolera. Es decir, como lo indican informes estadísticos de la Provincia de Neuquén (DPECPN, 2014), los niveles de ocupación entre hombres y mujeres en determinadas zonas, como en la denominada VI, que incluye el Departamento de Pehuenches y la localidad de Rincón de los Sauces, presentan grandes diferencias. Por ejemplo, la Encuesta Provincial de Hogares arrojó para el 2012 un índice del $67.7 \%$ de ocupación de los hombres, frente a un $32.7 \%$ de las mujeres ${ }^{11}$. De esta manera, Sara percibe que esas diferencias son problemáticas en las familias y entre los cónyuges por quién recibe los ingresos -los hombres- y por cómo se distribuyen las responsabilidades familiares y en el hogar, asignadas y predeterminadas por un orden de género hegemónico. Entonces, si bien las situaciones de los casos que ella atiende son diversas, Sara identifica que hay determinados perfiles tanto de hombres como de mujeres que se repiten en los casos que ella lleva adelante. Por ejemplo, dice que hay hombres que tienen hijos con más de una pareja, "¡diseminados por todo el pueblo!": "tenés 2 con una, 2 o 3 con otra, tenés una nueva familia. Ninguna de las mujeres labura, ¿me entendés? Entonces, todos los pibes del sueldo del pobre boludo, porque viéndolo ¡realmente es un pobre boludo!” Así, para ella, el supuesto "proveedor" de la mujer se ve sobrepasado en sus capacidades de atención y económicas en tanto las cuotas alimentarias son un alto porcentaje del sueldo, a su vez multiplicado por la cantidad de hijos que tenga.

11 El informe destaca en distintas ocasiones que estas diferencias se deben a la actividad hidrocarburífera predominante en esta zona y eminentemente masculina/masculinizada. Asimismo, destaca que, a diferencia de la ocupación de los hombres en "actividades primarias" (que incluye la petrolera), las mujeres se insertan laboralmente en actividades categorizadas como "de enseñanza", "servicios domésticos" y "comercio" (Dirección Provincial de Estadística y Censos de la Provincia de Neuquén 2012). 
Así, la abogada contó que en caso de ser su cliente el hombre, a veces no le alcanza el dinero ni siquiera para pagarle a ella, mientras que hay otros que tienen un gran poder adquisitivo que no quieren hacerse cargo de sus obligaciones como padres. Pero también, a partir de lo que ella observa y atiende, habló de las mujeres y distinguió entre "las que se enamoran y tienen hijos" como un proyecto genuino de familia y "las vivas" que tienen " 1 con vos, 1 con vos, 1 con vos. 4 pibes, 4 cuotas alimentarias", que "se hacen un sueldo petrolero" y reciben bienes como una casa o auto.

De esta manera, y a partir del conocimiento que tiene desde su trabajo, Sara discrimina entre las "buenas" y "malas" mujeres o madres que, nuevamente, son valoradas a partir de sus prácticas sexoafectivas con más de un hombre y también de cuán "mantenidas" sean. Aquí, por un lado, se pone en juego la valoración positiva de los involucramientos afectivos que se consideran verdaderos, más apegados a la idea de amor romántico y al desinterés económico, en contraposición con el estigma que recae sobre la libertad sexual y las consecutivas o simultáneas relaciones donde la mujer obtiene ventajas económicas a través de la maternidad.

Como señala Eva Illouz (2009), en el capitalismo tardío se ha producido la mercantilización del romance en tanto el amor aparece vinculado o próximo a los bienes, el dinero y el consumo. Sin embargo, "este nuevo modelo del matrimonio no logra anular por completo los modelos anteriores, basados en la colaboración y en los valores familiares tradicionales" (Illouz, 2009 p. 89). Ante esta tensión, la autora propone considerar que la racionalidad económica que estructura los encuentros románticos está imbricada con el desinterés y la emotividad pura. Y en este sentido, nos recuerda la propuesta de Zelizer (2009) de reconciliar los mundos hostiles porque, efectivamente, en la práctica las personas los entremezclan.

Es así que los interlocutores, tanto hombres como mujeres, expresan, a través de sus discursos, sentidos donde las dimensiones afectivas y económicas se entremezclan y, según la situación, las consideran juntas, separadas o confundidas. Por ejemplo, y regresando al caso de Katy, a ella no le fue suficiente que su pareja le diera todo, económicamente hablando, además del apoyo moral para poder sostener a sus hijos, sino que le faltó el amor, aunque dice haber querido mucho a esa pareja que eligió, por el respeto mutuo y la costumbre de estar con él. De hecho, la consecuente separación no tuvo que ver con su decisión, sino con la de él, hecho que Katy vivió con mucha angustia: "sabes qué feo cuando alguien te dice que no te quiere más y que no hay forma, y encima que vos no tengas con qué defenderte en la vida, que tengas tu laburo, no tenés nada, te quedas en la calle".

A partir de esta narración sobre los sucesos que tuvieron lugar en la relación de 6 años con Alan, Katy remitió al fracaso amoroso o a cómo él se desenamoró de ella y a la forma en que puso en valor ese vínculo cuando se terminó, diez años atrás. No obstante, 
trajo nuevamente la dimensión material que significaba esa pareja, como un "modo de sostener la vida" (Narotzky \& Besnier, 2014) tanto para ella como para sus hijos, porque además de sentirse afectada emocionalmente por el rechazo de él, no tenía autonomía económica. Ahí fue cuando un amigo le dijo que "el matrimonio es una sociedad, un negocio" y le sugirió que le dijera a su pareja: "me das tanto y me voy. Así, ¿querés libertad? ¿querés estar con quien quieras? Bueno, así te vale la libertad." Y a partir de este consejo, Katy le pidió 50000 pesos, hace diez años, para poder irse de Caleta Olivia con su familia, y él accedió. Le dio los ahorros que tenía y otro dinero que consiguió prestado, y ella preparó la mudanza y se fue mientras él trabajaba.

A partir de estas situaciones y de otras que entraman lo económico con lo sexoafectivo, surgen una serie de valoraciones para juzgar tanto las propias prácticas como las de otros(as), así como se difunden prejuicios y se construyen estereotipos de hombres y mujeres en estos contextos petroleros. Mientras Gerardo parece juzgar más a las mujeres "particulares" que a las "profesionales", porque a pesar de que "ambas van tras el dinero", las segundas lo explicitan, mientras las primeras lo encubren, Hugo considera que el asunto económico está presente en la relación, y que ese no es un problema. No obstante, si no se intercambia con el "buen" cuidado que debe realizar una mujer en el hogar y para el marido, esa falta de importancia en el dinero puede ser puesta en cuestión. Así como recae un prejuicio sobre las mujeres que tienen hijos con más de un hombre, habitualmente petrolero, y se las considera "vivas", aunque también son las que realizan el trabajo reproductivo y las que dependen económicamente, con las violencias que esto puede implicar.

En lo que respecta a los hombres, también opera una clasificación social que los distingue entre "el que se hace cargo", lo que lo convierte en buen padre y marido, que cumple con su rol masculino de proveedor; el que, por el contrario, desatiende sus obligaciones, aunque pueda seguir respondiendo económicamente, y pone en jaque su hombría, aunque la sostiene con la "doble vida" que supone la "infidelidad"; o el que las atiende excesivamente convirtiéndose en el "pobre boludo", víctima de "mujeres abusivas" que solo quieren su dinero y utilizan a los hijos para obtenerlo. Con esto quiero decir que nada es tan lineal, transparente o evidente cuando se trata de relaciones conyugales o de pareja y de las representaciones que se reproducen o cuestionan sobre ellas. No obstante, es la multiplicidad de sentidos sobre la economía, la emoción y la sexualidad en la relación conyugal y en la familia, a su vez regulados por un orden de género específico, la que configura las relaciones sociales entre hombres y mujeres en los contextos petroleros en particular. 


\section{A modo de cierre: economías sexoafectivas con final abierto}

Para terminar, quiero señalar que las experiencias de las mujeres y de los hombres en las zonas petroleras pueden ser similares respecto de los relacionamientos sexoafectivos y de lo que conllevan, haya iniciado o no el vínculo a través del sexo comercial con los que luego se convirtieron en sus novios(as), maridos, esposas, amantes o parejas. Es decir, a pesar de que esos vínculos no persistan, ponen en juego o sacan a relucir afectos, necesidades, bienes, amor, obligaciones, reciprocidades, deudas, deberes morales, entregas, cuidados y deseos, que hacen menos predecibles las relaciones y las estructuras familiares. De esta manera, las experiencias y discursos presentados nos hablan de las complejidades de los proyectos conyugales, y de las situaciones que deben afrontarse según las características de esas relaciones y de su constitución, pero también de acuerdo con las formas de apoyo mutuo - con mayor o menor dificultad y valoración- que, a la vez, dan lugar al crecimiento personal, familiar y a las posibilidades de movilidad, de "sostener la vida" y de "una vida mejor", en términos económicos, pero también afectivos.

Así, ante el habitual prejuicio que recae sobre las mujeres "profesionales" o "particulares" que "cazan petroleros", como sobre los hombres petroleros que son "usados" o "que se meten con putas", las vidas íntimas exhiben resistencias y resignificaciones de esos lugares comunes, demostrando que no es tan simple y, sobre todo, que pese a los problemas y aspectos negativos, el acompañamiento también ofrece beneficios mutuos. Estos beneficios pueden medirse en términos de interés material por parte de las mujeres y sexual, por parte de los hombres, lo que también es un lugar común. No obstante, esos vínculos tienen más relevancia si se conciben en términos de lo que significan y representan: determinaciones o estrategias contextuales en vidas estructuradas por las desigualdades socioeconómicas y de género, que afectan tanto a los hombres como a las mujeres que se encuentran en un tiempo y un lugar específico.

Haber traído a este texto una diversidad de significados sobre la intimidad afectiva y económica de distintos interlocutores e interlocutoras, y volverlas, de cierto modo, públicas, tuvo la finalidad de mostrar la intensa articulación entre esas dos esferas que se suponen separadas y que se evalúan positivamente solo si permanecen así. Además, permitió observar cómo las personas producen categorías, las evalúan, y entrelazan o separan esos mundos hostiles, produciendo nuevos tránsitos de uno a otro. Recuperar esas subjetividades vividas y sentidas, con mayor o menor cercanía o implicación en el mercado sexual y desde distintas formas de participación, posibilita ver la diversidad de valoraciones que existen sobre ese entramado comercial y emocional y, también, cuáles son las búsquedas, aspiraciones, necesidades y consecuencias de las decisiones de las actoras y los actores. 
Analizar las experiencias conyugales a través de sus tensiones implica no limitar a las mujeres a la pasividad habitual y culturalmente atribuida a ellas, ni celebrar su total empoderamiento a partir del supuesto cálculo económico de esos relacionamientos, así como tampoco significa circunscribir las prácticas de los hombres únicamente a expresiones del poder masculino. Abordar los relacionamientos, así como sus prácticas y significados en tensión, supone asumir que los órdenes sexo-genéricos están en constante disputa, tanto en la acción como en la representación, y que, quienes se mueven dentro o a partir de ellos, los reproducen al tiempo que los resisten y transforman. A su vez, cabe decir que las representaciones de esas relaciones entre hombres y mujeres en los contextos petroleros también están reguladas por los significados de la familia, y sus implicancias en el orden social y productivo. Es decir, para narrar sus vínculos íntimos los(as) interlocutores(as) recurrieron a repertorios experienciales y morales que interpelan constantemente a las ideas tradicionales de la familia, el amor y el dinero, y los sentidos específicos que las personas producen sobre ellos a partir de las economías sexoafectivas que configuran sus relaciones. A partir de ello, debemos atender y entender que estudiar la economía a través de estas aproximaciones es una posibilidad de introducirnos en los modos en la que esta se manifiesta, pero, sobre todo, en los modos como "se hace" en la vida íntima.

\section{Referencias}

Abramowski, A. \& Canevaro, S. (2017). Pensar los afectos. Aproximaciones desde las ciencias sociales y las humanidades. Los Polvorines, Argentina: Universidad Nacional de General Sarmiento.

Agustín, L. M. (2007). Sex at the margins. Migration, Labour Markets and the Rescue Industry. Londres: Zed Books.

Balbi, F. (2007). De leales, desleales y traidores. Valor moral y concepción de política en el peronismo. Buenos Aires: Antropofagia.

Barrionuevo, N. (2016). Trabajo petrolero y desigualdades de género en Comodoro Rivadavia: reactualizaciones históricas. Identidades, 3(6), 88-109.

Bourdieu, P. (1997). Razones prácticas. Sobre la teoría de la acción. Barcelona: Anagrama.

Brook, H. (2015). Conjugality: Marriage and Marriage-Like Relationships Before the Law. Nueva York: Palgrave Macmillan.

Cabrapan Duarte, M. \& Jiménez Portilla, L. (2020). La espacialización del mercado del sexo en tiempos de regímenes antitrata. Reflexiones a partir de dos estudios de caso 
en Argentina y México. Espacios, géneros y sexualidades. Reflexiones feministas sobre las diferencias espaciales. Ciudad de México: Universidad Autómoma Metropolitana.

Callaway, H. (1992). Ethnography and experience: gender implications in fieldwork and texts. En J. Okely \& H. Callaway (Eds.), Anthropology and autobiography (pp. 29-48). Nueva York: Routledge.

Constable, N. (2003). Romance on a Global Stage: Pen Pals, Virtual Ethnography, and "Mail Order" Marriages. Londres: University of California Press.

Constable, N. (2009). The Commodification of Intimacy: Marriage, Sexand Reproductive Labour. Annual Review of Anthropology, 38, 9-64. https://doi.org/10.1146/annurev. anthro.37.081407.085133

Delphy, C. \& Leonard, D. (1992). Familiar Exploitation: A New Analysis of Marriage in Contemporary Western Societies. Cambridge: Polity Press.

Dirección Provincial de Estadística y Censos de la Provincia del Neuquén (DPECPN). (2012). Información municipal básica de la provincia del Neuquén. Vol. 14. Publicación Interactiva.

Dirección Provincial de Estadística y Censos de la Provincia del Neuquén (DPECPN). (2014). Las mujeres y los jóvenes ocupados. El empleo en el interior de la Provincia en la última década. Publicación Interactiva.

Dworkin, A. (1989). Pornography: Men Possessing Women. Nueva York: E. P. Dutton.

Fassin, D. (2012). Introduction: Toward a Critical Moral Anthropology. En D. Fassin (Ed.), A companion to moral anthropology (pp. 1-18). John Wiley \& Sons. https://doi. org/10.1002/9781118290620.ch

Hakim, C. (2012). Capital erótico: pessoas atraentes são mais bem-sucedidas. A ciência garante. Rio de Janeiro: Best Business.

Hiller, R. (2016). Mapeando la conyugalidad en una ciudad petrolera. Memoria Académica. Recuperado de http://www.memoria.fahce.unlp.edu.ar/trab_eventos/ev.8474/ ev.8474.pdf

Hochschild, A. R. (1979). Emotion Work, Feeling Rules, and Social Structure. American Fournal of Sociology, 85(3), 551-575.

Hofmann, S. \& Moreno, A. (2016). Introduction: Global Intimate Economies: Discontents and Debates. En S. Hofmann \& A. Moreno (Comps.), Intimate Economies. Bodies, Emotions, and Sexualities on the Global Market (pp. 1-30). Nueva York, Palgrave. 


\section{"ĊI'F= 37}

Revista CIFE / ISSN: 0124-3551 e-ISSN: 2248-4914 / Bogotá-Colombia / Vol. 22 N. 37 / julio-diciembre 2020 / pp. $139-161$

Illouz, E. (2009). El consumo de la utopía romántica: El amor y las contradicciones culturales del capitalismo. Buenos Aires: Katz Editores.

Irwin, K. (2007). En el oscuro corazón de la etnografía. Ética y desigualdades en las relaciones íntimas al interior del campo. Apuntes de Investigación del Cecyp, 12, 133-163.

Jelin, E. (1984). Familia y unidad doméstica: mundo público y vida privada. Buenos Aires: Centro de Estudios de Estado y Sociedad.

Massey, D. (1994). Space, place and gender. University of Minnesota Press.

Mauss, M. (1979). Ensayo sobre los dones. Motivo y formas del cambio en las sociedades primitivas. Sociología y antropología. Madrid: Editorial Tecnos.

McDowell, L. (2000). Género, identidad y lugar: un estudio de las geografías feministas. Valencia: Universitat de València.

Mead, M. (2006). Sexo y temperamento en tres sociedades primitivas. Barcelona: Paidós.

Narotzky, S. \& Besnier, N. (2014). Crisis, Value, and Hope: Rethinking the Economy: An Introduction to Supplement. CurrentAnthropology, 55(9), S4-S16. DOI: https://doi. org/10.1086/676327

Ortner, S. B. (1972). Is Female to Male as Nature Is to Culture? Feminist Studies, 1(2), 5-31. DOI: http://doi.org/10.2307/3177638

Palermo, H. (2017). La producción de la masculinidad en el trabajo petrolero. Buenos Aires: Editorial Biblos. DOI: https://doi.org/10.17345/rio20.250-252

Pateman, C. (1995). El contrato sexual. Barcelona: Anthropos Editorial.

Piscitelli, A. (2005). Apresentação: gênero no mercado do sexo. Cadernos Pagu, 25, 7-23. DOI: https://doi.org/10.1590/S0104-83332005000200001

Piscitelli, A. (2013). Trânsitos: brasileiras nos mercados transnacionais do sexo. Rio de Janeiro: Eduerj.

Piscitelli, A. (2016). Economias sexuais, amor e tráfico de pessoas - novas questões conceituais. Cadernos Pagu, 47, e16475. DoI: http://dx.doi.org/10.1590/18094449 201600470005

Piscitelli, A., De Oliveira Assis, G. \&. Nieto Olivar, J. M. (Coords.). (2011). Gênero, sexo, amor e dinheiro: mobilidades transnacionais envolvendo o Brasil. Campinas: Unicamp. 
Rosaldo, M. (1979). Mujer, cultura y sociedad: una visión teórica. En O. Harris \& K. Young (Comps.), Antropología y Feminismo (pp. 153-181). Barcelona: Editorial Anagrama.

Serret, E. (2006). El género y lo simbólico. La constitución imaginaria de la identidad femenina. Oaxaca: Instituto de la Mujer Oaxaqueña.

Strathern, M. (2006). O genero da dádiva: problemas com as mulheres e problemas com a sociedade na Melanésía. André Villalobos, traductor. Campinas: Unicamp.

Thompson, E. P. (1995). Costumbres en común. Barcelona: Crítica.

Vega, C. \& Gutiérrez Rodríguez, E. (2014). Nuevas aproximaciones a la organización social del cuidado. Debates latinoamericanos. Íconos. Revista de Ciencias Sociales, 50, 9-26.

Zelizer, V. (2009). La negociación de la intimidad. México: Fondo de Cultura Económica. 